\title{
Comparison of Orchard-grass and Sweet Maize for Doubled Haploid Plant Production via Wide Hybridization in Bread Wheat
}

\author{
Süleyman Avcı ${ }^{1, a, *}$, İmren Kutlü ${ }^{2, b}$ \\ ${ }^{1}$ Department of Field Crops, Faculty of Agriculture, Eskişehir Osmangazi University, 26160 Eskişehir, Turkey \\ ${ }^{2}$ Department of Biosystem Engineering, Faculty of Agriculture, Eskişehir Osmangazi University, 26160 Eskişehir, Turkey
} *Corresponding author

A R T I C LE INFO A B S T R A C T

Research Article In this study, the potential of haploid regeneration was investigated in hybridization of six bread wheat $\mathrm{F}_{1}$ hybrids known response to another culture with orchard-grass (Dactylis glomerata $\left.\mathrm{L}.\right)$ and sweet maize varieties (Baron, Challenger and Merit). A total of 150 wheat spikes were pollinated with orchard grass and sweet maize and 2730 pseudo-seeds were produced. Although

Received : $15 / 03 / 2020$ the high rate of developed pseudo-seeds was developed from bread wheat $\mathrm{F}_{1}$ hybrids $\times$ orchardgrass, no embryos were produced. Developed pseudo-seeds (2057 number) of bread wheat $\times$ sweet maize produced 53 haploid embryos and only 8 of them were regenerated. Developed green plantlets were vernalized and applied colchicine and only four of them produced fertile seeds. The highest rate (5.9) of haploid embryo formation within wheat genotypes was determined in $\mathrm{DH} 20$ $\times$ Kate A-1. Although the highest haploid embryo formation was observed in Challenger with $3.5 \%$ among sweet maize genotypes, it had no effect on plant regeneration. Also, the mixture of pollen of sweet maize varieties increased haploid plant regeneration. It has been observed that some $\mathrm{F}_{1}$ hybrids such as DH $20 \times$ Kate A- 1 and DH6 $\times$ Altay 2000 with low anther response gave better results in terms of haploid embryo formation and regeneration. The means of fertile spike percentages and number of seeds per fertile spike were $26.75 \%$ and 9.83 , respectively in developed green plants. As a result, bread wheat $\times$ sweet maize hybridization will be a good alternative to obtain a homozygous line in a short time in bread wheat genotypes with low anther response.

F1 generation Hybridization Embryo rescue Maternal haploid Pseudo-seeds

\section{Introduction}

In wheat, which is vital for human nutrition, the limit of genetic variability has been approached to solve yield and quality problems. Accelerated breeding technologies are required for establishing wide variability in a short time, improve the efficiency of the selection, and quicken the occurring of new varieties. Double haploid technology is widely used for these aims. Producing numerous genotypes, economically, is related to use haploids in a wheat breeding program effectively. The most important advantage of using haploids is to offer the possibility of obtaining complete homozygosity.

Haploid plants in wheat can be obtained in artificial nutrient media by using anther and microspore cultures and wide hybridization of wheat with maize, cogongrass, etc. (Dang et al., 2011; Prasanna et al., 2012). Although anther and microspore culture are more widely used because they are easily applied methods, the root system of the regenerant plant produced with a wide hybridization is healthier, and no albino plant formation is observed, which makes this method advantageous (Niu et al., 2014). Wheat $\times$ maize wide hybridization requires intensive workload; however, many researchers suggest that it is the most reliable and practical method in wheat breeding (Campell et al., 2000; Garcia-Llamas et al., 2004).

Growth conditions, pollen sources, plant growing methods, and wheat genotypes are important factors for producing doubled haploid plants, as well as the types and concentrations of the chemicals used (Knox et al., 2000). In previous studies, the effects of wheat genotype (Ltifi et al., 2019), pollen sources (Ding et al., 2019), emasculation methods (Patial et al., 2019) and hormone applications (Warchoł et al., 2016) on haploid plant regeneration of wheat were investigated. 
In addition to maize, Pennisetum glaucum L. (Inagaki and Mujeeb-Kazi, 1995), sorghum (Maluszynski et al., 2003) and Imperata cylindrica (L.) Raeusch. (Chaudhary et al., 2005) species have been used to obtain haploid plants by wide hybridization with wheat. Zenkteler and Nitzsche (1984) reported that wheat, barley and rye were tested for haploid embryo formation with 15 species of Poaceae and Panicoideae and embryo formation can be obtained with Agropyron repens (L.) P. Beauv., Alopecurus agrestis L., Dactylis glomerata L., Pennisetum americanum L. and Zea mays L. However, it is important to investigate undiscovered pollen sources that will provide high haploid regeneration in different wheat genotypes and hybrids.

In this study, the potential of haploid plant regeneration was investigated by crossing six bread wheat $\mathrm{F}_{1}$ hybrids, response to another culture are known, with sweet maize (Z. mays var. saccharata) and orchard-grass (D. glomerata).

\section{Materials and Methods}

In the study, six bread wheat $\mathrm{F}_{1}$ hybrids known anther culture response were used and their features were shown in Table 1. As an inducer, the population of orchardgrass (D. glomerata) which is distributed in Campus of Agriculture Faculty, Eskişehir Osmangazi University, and sweet maize (Z. mays var saccharata) varieties [(Baron (B), Challenger (C) and Merit (M)] and mixture pollen of maize (MP) were used.

After wheat seedlings were vernalized at $4^{\circ} \mathrm{C}$ for 5 weeks, they were grown in pots containing soil, peat and vermiculite (3:2:1). Maize seeds were sown periodically every week at four times, and the flowering period of the wheat plant was provided to coincide with maize. Wheat spikes that slightly emerged from flag leaves were emasculated, and then these spikes were covered with isolation envelopes. Emasculated spikes were pollinated with inducer plants within 1-3 days. 2.4-D solution (213.05 $\mathrm{mg} / \mathrm{l}, \mathrm{pH}=10.36$ ) was applied within 24-48 hours following hybridization to support healthy embryo formation as described by Niu et al. (2014).

Spikes were collected at 16-19 days after fertilization and the pseudo-seeds were removed from the spikes. Picked pseudo-seeds were sterilized in $70 \%$ alcohol for 1 minute. Then, they were kept in $20 \%$ bleach (Domestos, $4.26 \%$ sodium hypochlorite) for 15 minutes and rinsed with sterile distilled water at least 3 times. The haploid embryos were carefully removed from pseudo-seeds under a stereo microscope and cultured on MS medium (Murashige and Skoog, 1962) containing 5\% sugar and, $0.7 \%$ agar and were kept in the dark condition at $22 \pm 0.5^{\circ} \mathrm{C}$ for $1-2$ weeks. Germinated embryos were transferred in $1 / 2$ MS media containing 3\% sugar and $0.7 \%$ agar and kept for 2 weeks under the photoperiod of $16 / 8$ (light/dark) at $22 \pm 0.5^{\circ} \mathrm{C}$. When plants growing from haploid embryos reached to 5-6 cm, they were transferred to pots containing peat and vermiculite (3:1). Haploid plants with 2-3 tillers were removed without damaging their roots and colchicine doubling solution [colchicine $(0.45 \mathrm{~g} / \mathrm{l})+$ DMSO $(20 \mathrm{ml} / \mathrm{l})+\mathrm{GA}_{3}(100 \mathrm{mg} / \mathrm{l})+$ Tween $80(0.3 \mathrm{ml} / \mathrm{l}), \mathrm{pH}=5.5]$ was applied (Niu et al., 2014). These treated plants were rinsed under tap water overnight, and then they were planted to pots again and transferred to the climate cabinet at $18 \pm 0.5^{\circ} \mathrm{C}$ and $75 \%$ humidity.

Chromosome observations were performed by modifying the method as described by Arslan et al. (2012). First, root tips of haploid plants were kept in alpha-monobromonaftalin solution for 3 hours and then fixed in glacial acetic acid for 30 minutes at room temperature. The fixed root tips were hydrolysed in $1 \mathrm{~N}$ $\mathrm{HCL}$ for 12 minutes at $60^{\circ} \mathrm{C}$. Then, root tips were left to be stained for $1-1.5$ hours in $1 \%$ aceto-orsein solution.

The data of individual factors were given with standard error and interaction between wheat and maize genotypes was measured by the chi-squared test $\left(\chi^{2}\right)$ for developed pseudo-seeds, embryo, and plantlets.

\section{Results and Discussion}

The successful application of wide hybridization in wheat breeding programs is dependent on ability to form pseudo-seeds, embryo and plant regeneration of the genotypes. In this study, a total of 2730 pseudo-seeds were obtained from pollinated 150 wheat spikes, and 53 of them $(1.94 \%)$ generated haploid embryos. Only $8(0.29 \%)$ of the haploid embryos were regenerated, and $4(0.14 \%)$ of them were improved seed set.

The effect of wheat $F_{1}$ hybrids on developed pseudoseeds, embryo formation, and plant regeneration indicated differences (Table 2). The highest number of developed pseudo-seeds, embryo formation and plant regeneration were recorded in DH6 $\times$ Altay 2000, DH20 × Kate A-1 and DH21 $\times$ Kate A-1, respectively. High numbers of developed pseudo-seeds and embryo-forming wheat $F_{1}$ hybrids did not produce a high number of green plants. It is still a controversial issue of whether haploid embryo formation was affected by wheat and maize genotypes. Some researchers observed embryo percentage affected only by maize cultivars, not wheat genotypes, whereas numerous other studies proved wheat genotypes distinctly affect the production of embryos per florets (Filomena Martins-Lopes et al., 2001; Niroula and Thapa, 2009, Xynias et al., 2014).

Table 1. Pedigree of $F_{1}$ hybrids used as donor plant and their anther culture response.

\begin{tabular}{l|rrrr}
\hline \multicolumn{1}{c|}{ Pedigree } & Callus induction & Plant regeneration & Fertile plants & Gained seeds \\
\hline DH6 $\times$ Altay 2000 & 22 & 2 & 0 & 0 \\
DH18 $\times$ Altay 2000 & 75 & 0 & 0 & 0 \\
DH18 $\times$ Kate A-1 & 111 & 3 & 3 & 205 \\
DH19 $\times$ Altay 2000 & 152 & 17 & 5 & 351 \\
DH20 $\times$ Kate A-1 & 13 & 0 & 0 & 0 \\
DH21 $\times$ Kate A-1 & 119 & 16 & 4 & 458 \\
\hline
\end{tabular}

*The values shown in the table were obtained from the previous study (Kutlu et al., 2019) 
Table 2. Effect of wheat $F_{1}$ hybrids on the yield of developed pseudo-seeds, embryos and plants

\begin{tabular}{l|ccc}
\hline \multicolumn{1}{c|}{ Wheat F1 hybrids } & Developed pseudo-seeds (n) & Embryos & Plants \\
\cline { 2 - 5 } DH6 $\times$ Altay 2000 & 117 & 2.9 & $\%$ \\
DH18 $\times$ Altay 2000 & 85 & 0.6 & 0.4 \\
DH18 $\times$ Kate A-1 & 74 & 0.7 & 0.4 \\
DH19 $\times$ Altay 2000 & 108 & 1.7 & 0.0 \\
DH20 $\times$ Kate A-1 & 90 & 5.9 & 0.5 \\
DH21 $\times$ Kate A-1 & 72 & 2.5 & 0.3 \\
Standard error & 4.3 & 1.4 & 0.7 \\
\hline
\end{tabular}

*Percentage values were calculated using the following formula: (Embryo or Plant numbers/Developed pseudo seeds) $\times 100$

Table 3. Effect of inducers on the yield of developed pseudo seeds, embryos and plants

\begin{tabular}{|c|c|c|c|}
\hline \multirow{2}{*}{ Inducers } & \multirow{2}{*}{ Developed pseudo seeds (n) } & Embryos & Plants \\
\hline & & $\% *$ & $\%$ \\
\hline Baron & 97 & 2.1 & 0.2 \\
\hline Challenger & 93 & 3.5 & 0 \\
\hline Merit & 70 & 1.0 & 0.3 \\
\hline Pollen mixture of maize & 83 & 3.4 & 1.2 \\
\hline Orchard-grass & 112 & - & - \\
\hline Standard error & 4.0 & 1.0 & 0.7 \\
\hline
\end{tabular}

*Percentage values were calculated using the following formula: (Embryo or Plant numbers/Developed pseudo seeds) $\times 100$

Table 4. The effect of bread wheat $\mathrm{F}_{1}$ hybrids $\times$ inducers interaction on developed pseudo seeds (number)

\begin{tabular}{l|rrrrr}
\hline \multirow{2}{*}{ Wheat $F_{1}$ hybrids } & \multicolumn{5}{c}{ Inducers } \\
\cline { 2 - 6 } & Baron & Challenger & Merit & Mixture of maize & Orchard-grass \\
\hline DH6 $\times$ Altay 2000 & 134 & 113 & 53 & 122 & 161 \\
DH18 $\times$ Altay 2000 & 78 & 81 & 47 & 86 & 132 \\
DH18 $\times$ Kate A-1 & 75 & 89 & 48 & 71 & 88 \\
DH19 $\times$ Altay 2000 & 108 & 76 & 106 & 100 & 150 \\
DH20 $\times$ Kate A-1 & 106 & 114 & 96 & 59 & 76 \\
DH21 $\times$ Kate A-1 & 82 & 86 & 67 & 60 & 66 \\
\hline
\end{tabular}

Interaction is significant at $\mathrm{P}=0.01(\mathrm{df}=20)$ since the calculated $\chi^{2}=105.6>$ theoretical $\chi^{2}=37.56$.

Table 5. The effect of bread wheat $\mathrm{F}_{1}$ hybrids $\times$ inducers interaction on embryo formation (\%)

\begin{tabular}{l|cccc}
\hline \multirow{2}{*}{ Wheat F1 hybrids } & \multicolumn{4}{c}{ Inducer } \\
\cline { 2 - 5 } & Baron & Challenger & Merit & Pollen mixture of maize \\
\hline DH6 $\times$ Altay 2000 & 2.2 & 3.5 & 0 & 5.7 \\
DH18 $\times$ Altay 2000 & 1.2 & 0 & 0 & 1.2 \\
DH18 $\times$ Kate A-1 & 0 & 1.1 & 2 & 0 \\
DH19 $\times$ Altay 2000 & 0 & 3.9 & 0 & 4 \\
DH20 $\times$ Kate A-1 & 7.5 & 7.9 & 0 & 6.8 \\
DH21 $\times$ Kate A-1 & 0 & 3.5 & 4.5 & 1.7 \\
\hline
\end{tabular}

Interaction is significant at $\mathrm{P}=0.01(\mathrm{df}=15)$ since the calculated $\chi^{2}=33.0>$ theoretical $\chi^{2}=30.5$.

In terms of the inducer effect on haploid plant regeneration, wheat $\mathrm{F}_{1}$ hybrids $\times$ D. glomerata hybridization produced a high rate of developed pseudoseeds (Table 3). However, none of them had haploid embryos after 16-19 days. Zenkteler and Nitzsche (1984) reported that a high rate of embryos was obtained from wheat $\times D$. glomerata hybridization, but the embryos disappeared after ten days. In terms of embryo formation, Challenger and pollen mixtures of sweet maize showed similar results. However, the effect of the pollen mixture of sweet maize on plant regeneration was found to be higher. Zhang et al. (1996) observed that the effect of maize genotypes on embryo formation and plant regeneration was important, and the effect of wheat genotypes was insignificant.
While the highest developed pseudo-seeds were observed in the hybridization of DH6 $\times$ Altay 2000 with low anther response and D. glomerata, the lowest value was obtained from DH18 $\times$ Altay 2000 and Merit hybrid (Table 4). The highest value $(7.9 \%)$ for embryo formation occurred in the $\mathrm{DH} 20 \times$ Kate A-1 with low anther response and Challenger hybrid (Table 5). In terms of plant regeneration from haploid embryos, the effect of interaction was found insignificant (Table 6). Although Challenger induced the high rate of embryo formation in wheat $F_{1}$ hybrids, its effect was not observed in plant regeneration. Lefebvre and Devaux (1996) and Cherkaoui et al. (2000) reported that wheat $\times$ maize interaction was significant in haploid embryo formation and plant regeneration. 
Table 6. The effect of bread wheat $\mathrm{F}_{1}$ hybrids $\times$ inducers interaction on plant regeneration $(\%)$

\begin{tabular}{l|ccc}
\hline \multirow{2}{*}{ Wheat F1 genotypes } & \multicolumn{3}{c}{ Inducer } \\
\cline { 2 - 4 } & Baron & Merit & Pollen mixture of maize \\
\hline DH6 $\times$ Altay 2000 & 0 & 0 & 1.7 \\
DH18 $\times$ Altay 2000 & 1.3 & 0 & 0 \\
DH18 $\times$ Kate A-1 & 0 & 0 & 0 \\
DH19 $\times$ Altay 2000 & 0 & 0 & 2 \\
DH20 $\times$ Kate A-1 & 0 & 0 & 1.7 \\
DH21 $\times$ Kate A-1 & 0 & 1.5 & 1.7 \\
\hline
\end{tabular}

Interaction is not significant at $\mathrm{P}=0.01(\mathrm{df}=10)$ since the calculated $\chi^{2}=13.3<$ theoretical $\chi^{2}=23.2$.

Table 7 . Some characters of regenerated plants in wheat $\times$ maize hybrids

\begin{tabular}{l|ccccc}
\hline \multirow{2}{*}{ Characters } & \multicolumn{4}{c}{ Wheat $\times$ sweet maize hybrids } \\
\cline { 2 - 6 } & $\begin{array}{c}\text { DH21 } \times \text { Kate A- } \\
1 \times \mathrm{MP}\end{array}$ & $\begin{array}{c}\text { DH6 } \times \text { Altay } \\
2000 \times \mathrm{MP}-1\end{array}$ & $\begin{array}{c}\text { DH6 } \times \text { Altay } \\
2000 \times \mathrm{MP}-2\end{array}$ & $\begin{array}{c}\text { DH21 } \\
1 \times \text { Kate A- }\end{array}$ & \multirow{2}{*}{ Mean } \\
\hline Fertile spike $(\%)$ & 19.3 & 9.7 & 40.0 & 38 & 26.75 \\
Seed number per fertile tiller & 13.5 & 1.3 & 10.5 & 14 & 9.83 \\
\hline
\end{tabular}

MP and M indicate pollen mixture of sweet maize and cv. Merit, respectively.

Among the wheat genotypes, only plants obtained from DH6 $\times$ Altay 2000 with low anther response and DH21 $\times$ Kate A-1 with high anther response genotypes have produced seeds (Table 7). The number of fertile spikes ranged from $9.7 \%$ in DH6 $\times$ Altay $2000 \times$ MP-1 to $40 \%$ in DH6 $\times$ Altay $2000 \times$ MP-2, and the mean fertile spike was $26.75 \%$. The mean seed number per fertile spike was 9.83 and the lowest value was obtained from DH6 $\times$ Altay $2000 \times$ MP-1. In the previous study indicated in Table 1, no plants were obtained from the combination of DH6 $\times$ Altay 2000 among these genotypes by the anther culture method (Kutlu et al., 2019). It is a pleasing result to obtain high number of seeds from two plants obtained by the wheat $\times$ maize crossbreeding method.

Consequently, the efficiency of D. glomerata and sweet maize genotypes for haploid plant production in some bread wheat $F_{1}$ hybrids were determined. Even though there was a high rate of developed pseudo-seeds in the wheat $\times$ orchard-grass hybrids, no haploid embryo was found. Thus, effects of different hormone type and times of embryo rescue should be evaluated for haploid embryo production between wheat and orchard grass cross. In wheat $\times$ sweet maize hybrids, four green plants in two different wheat $F_{1}$ hybrids were obtained. Differences in haploid plant regeneration were observed according to the wheat and maize genotypes. Achieving for haploid embryo formation and regeneration from wheat genotypes with a low anther culture response suggest that wheat $\times$ maize wide hybridization will be a good alternative to obtain efficient doubled haploid plant regeneration in bread wheat genotypes with low anther response. In genotypes with good anther response and good maternal haploids, the haploid technique to be used is optional. However, the high rate of albino plants may make it preferable to wide hybridization instead of anther technique. Although the source of the pollen to be used depends on the compatibility with the wheat genotypes to be used as a female parent, the effective one on many genotypes can be chosen. However, as proved in this study, applying maize pollen by mixing will guarantee embryo production.

\section{Acknowledgements}

This study was supported by Eskişehir Osmangazi

University under grant no: 2018-23D01.

\section{References}

Arslan E, Ertuğrul K, Tugay O, Dural H. 2012. Karyological studies of the genus Onobrychis Mill. and the related genera Hedysarum L. and Sartoria Boiss. \& Heldr. (Fabaceae, Hedysareae) from Turkey, Caryologia, 65 (1): 11-17, DOI: 10.1080/00087114. 2012.678079.

Campbell AW, Griffin WB, Burritt DJ, Conner AJ. 2000. Production of wheat doubled haploids via wide crosses in New Zealand wheat. New Zealand Journal of Crop and Horticultural Science, 28: 185-194. https://doi.org/10.1080/01140671.2000.9514138.

Chaudhary HK, Sethi GS, Singh S, Pratap A, Sharma S. 2005. Efficient haploid induction in wheat by using pollen of Imperata cylindrica. Plant Breeding, 124: 96-98. https://doi.org/ 10.1111/j.1439-0523.2004.01034.x.

Cherkaoui S, Lamsaouri O, Chlyah A, Chlyah H. 2000. Durum wheat $\times$ maize crosses for haploid wheat production: Influence of parental genotypes and various experimental factors. Plant Breeding, 119 (1): 31-36. DOI: 10.1046/j.14390523.2000.00433.x.

Dang NC, Munsch M, Aulinger I, Renlai W, Stamp P. 2011. Inducer line generated double haploid seeds for combined waxy and opaque 2 grain quality in subtropical maize (Zea mays L.). Euphytica, 183, pages153-160. DOI: 10.1007/ s10681-011-0423-0.

Ding M, Abdelkhalik S, Li H, Yang M, Li S, Gu J, Liu K. 2019. Influence of maize genotypes on wheat haploid embryos production in maize mediated cross system. Journal of Sustainable Agricultural Sciences, 45(1): 1-9. DOI: 10.21608/jsas.2019.7260.1129.

Garcia-Llamas C, Martin A, Ballesteros J. 2004. Differences among auxin treatments on haploid production in durum wheat $\times$ maize crosses. Plant Cell Reports, 23: 46-49. DOI: 10.1007/s00299-004-0786-y.

Inagaki M, Mujeeb-Kazi A. 1995. Comparison of polyhaploid production frequencies in crosses of hexaploid wheat with maize, pearl millet and sorghum. Japanese Journal of Breeding, 45(2): 157-161. https://doi.org/10.1270/jsbbs1951. 45.157.

Knox RE, Clarke JM, DePauw RM. 2000. Dicamba and growth condition effects on doubled haploid production in durum wheat crossed with maize. Plant Breeding, 119 (4): 289-298. https://doi.org/10.1046/j.1439-0523.2000.00498.x. 
Kutlu I, Sirel Z, Yorgancilar O, Yorgancilar A. 2019. Line $\times$ tester analyses for anther culture response of bread wheat (Triticum aestivum L.). Genetika, 51(2): 447-461. https://doi.org/ 10.2298/GENSR1902447K.

Lefebvre D, Devaux P. 1996. Doubled haploids of wheat from wheat $\mathrm{x}$ maize crosses: genotypic influence, fertility and inheritance of the 1BL-1RS chromosome. Theoretical Applied Genetics, 93: 1267-1273. https://doi.org/10.1007/BF00223459.

Ltifi A, Sahli A, Haouala F. 2019. Study of some factors influencing the production of durum wheat haploids by cross wheat $x$ maize. International Journal of Advances in Agricultural Science and Technology, 6(1): 17-23.

Maluszynski M, Kasha KJ, Forster BP, Szarejko I. 2003. Doubled haploid production in crop plants, A Manual, Kluwer Academic Publishers: p. 309-336. https://doi.org/10.1007/978-94-0171293-4.

Filomena Martins-Lopes P, Guedes-Pinto H, Pinto-Carnide O, Snape J. 2001. The effect of spikelet position on the success frequencies of wheat haploid production using the maize cross system. Euphytica, 121, 265-271. https://doi.org/10.1023/ A:1012091610195.

Murashige T, Skoog F. 1962. A revised medium for rapid growth and bioassays with tobacco tissue cultures. Physiologia Plantarum, 15: 473-497. https://doi.org/10.1111/j.13993054.1962.tb08052.x.

Niroula RK and Thapa DB. 2009. Response of wheat genotypes to maize mediated polyhaploid production. American-Eurasian Journal of Agronomy, 2(3): 156-161.
Niu Z, Jiang A, Hammad WA, Oladzadabbasabadi A, Xu SS, Mergoum M, Elias EM. 2014. Review of doubled haploid production in durum and common wheat through wheat $x$ maize hybridization. Plant Breeding, 133: 313-320. https://doi.org/10.1111/pbr.12162.

Patial M, Pal D, Thakur A, Bana RS, Patial S. 2019. Doubled haploidy techniques in wheat (Triticum aestivum L.): An overview. Proceedings of the National Academy of Sciences, India Section B: Biological Sciences, 89(1): 2741. https://doi.org/10.1007/s40011-017-0870-z.

Prasanna BM, Chaikam V, Mahuku G. 2012. Doubled haploid technology in maize breeding: Theory and Practice. Mexico, D.F.: CIMMTY. ISBN Number: 978-607-95844-9-8.

Warchoł M, Skrzypek E, Nowakowska A, Marcińska I, Czyczyło-Mysza I, Dziurka K, Cyganek K. 2016. The effect of auxin and genotype on the production of Avena sativa $\mathrm{L}$. doubled haploid lines. Plant growth regulation, 78(2): 155165. https://doi.org/10.1007/s10725-015-0082-6.

Xynias I, Koufalis A, Gouli-Vavdinoudi E, Roupakias D. 2014. Factors affecting doubled haploid plant production via maize technique in bread wheat. Acta Biologia Cracoviensia Series Botanica, 56(2): 67-73. DOI: 10.2478/abcsb-20140022.

Zhang J, Friebe B., Raupp WJ, Harrison SA. 1996. Wheat embryogenesis and haploid production in wheat $\times$ maize hybrids. Euphytica, 90: 315-324. https://doi.org/10.1007/ BF00027482.

Zenkteler M, Nitzsche W. 1984. Wide hybridization experiments in cereals. Theoretical and Applied Genetics, 68(4), 311-315. https://doi.org/10.1007/BF00267883. 